\title{
LOGROÑO (1901-1950)
}

\section{M. a Ángel SOMALO FERNÁNDEZ}

\author{
a-somalo@terra.es
}

Resumen: Reconstrucción de la cartelera teatral de Logroño entre 1901 y 1950, centrada exclusivamente en el teatro clásico español del Siglo de Oro, atendiendo a las obras y autores representados, compañías y recepción crítica.

Résumé: Reconstruction de l'activité théâtrale en la ville de Logroño entre 1901 et 1950 en ce qui concerne aux pièces du Siécle d'Or espagnol. Dramaturges et pièces, mise en scène, compagnies de théâtre et valorisation de la critique.

Palabras clave: Cartelera teatral. Historia del teatro representado. Logroño.

Mots clé: Rubrique des affiches. Histoire de la mise en scène. Logroño.

Vamos a enumerar en este artículo todas las representaciones de obras de nuestros clásicos que se efectuaron en la primera mitad del siglo XX en los escenarios logroñeses, realizadas tanto por compañías profesionales como 
por grupos de aficionados. A partir de esta relación obtendremos algunas conclusiones sobre este asunto.

Exponemos los autores representados por orden alfabético, y en cada uno las obras escenificadas, numeradas por funciones, con todos sus datos (fecha y hora de la función, autor de la adaptación en su caso, local donde se llevó a cabo, compañía que la puso en escena, director y fuente de la información), siguiendo la misma clasificación:

CALDERÓN DE LA BARCA, Pedro (1600-1681)

El alcalde de Zalamea [DRAMA]

(1)

29-IX-1908 (noche)

Teatro Bretón

Compañía Jiménez-Villagómez

La Rioja (29-IX-1908).

(2)

29-II-1912 (22 h.)

Teatro Bretón

Compañía dirigida por Francisco Morano

La Rioja (29-II-1912).

(3)

21-IX-1912 (22 h.)

Teatro Bretón

Compañía Francisco Morano

La Rioja (21-IX-1912).

(4)

2-X-1912 (18,30 h.)

Teatro Bretón

Compañía Francisco Morano

La Rioja (2-X.1912).

13-II-1915 (22 h.)

Teatro Moderno

Compañía Francisco Morano

La Rioja (13-II-1915). 
(6)

14-II-1915 (18,30 h.)

Teatro Moderno

Compañía Francisco Morano

La Rioja (14-II-1915).

(7)

21-IX-1919 (22,30 h.)

Teatro Bretón

Compañía Francisco Morano

La Rioja (21-IX-1919).

(8)

22-IX-1919 (19 h.)

Teatro Bretón

Compañía Francisco Morano

La Rioja (22-IX-1919).

(9)

22-IX-1921 (22,15 h.)

Teatro Bretón

Compañía Enrique Borrás

La Rioja (22-IX-1921).

(10)

23-IX-1921 (18,30 h.)

Teatro Bretón

Compañía Enrique Borrás

La Rioja (23-IX-1921).

(11)

13-I-1924 (22,15 h.)

Teatro Bretón

Compañía Francisco Morano

La Rioja (13-I-1924).

14-I-1924 (18,15 h.)

Teatro Bretón

Compañía Francisco Morano

La Rioja (13-I-1924). 
(13)

24-I-1930 (18,30 h.)

Refundición de Adelardo López de Ayala

Teatro Bretón

Compañía Francisco Morano

La Rioja (24-I-1930).

25-I-1930 (22,45 h.)

Refundición de Adelardo López de Ayala

Teatro Bretón

Compañía Francisco Morano

La Rioja (25-I-1930).

(15) y (16) 29-IV-1940 (19 y 22,30 h.)

Refundición de Carlos Moor

Teatro Bretón

Compañía Ricardo Calvo

Nueva Rioja (28-IV-1940).

(17) y (18) 28-II-1941 (18,30 y 22 h.)

Teatro Bretón

Varios grupos de aficionados

Nueva Rioja (27-II-1941).

(19) y (20) 25-VI-1943 (17,30 y 22,45 h.)

Teatro Lope de Rueda

Compañía Enguidanos

Nueva Rioja (23-VI-1943).

(21) y (22) 26-VI-1943 (17,30 y 22,45 h.)

Teatro Lope de Rueda

Compañía Enguidanos

Nueva Rioja (26-VI-1943).

(23) y (24) 18-V-1947 (19,30 y 22,45 h.)

Adaptación de Juan de La Peña 
Teatro Bretón

Compañía Demetrio Alfonso

Nueva Rioja (18-V-1947).

La vida es sueño [DRAMA]

(1)

5-V-1902

Teatro Bretón

Compañía Francisco Fuentes

La Rioja (5-V-1902).

(2)

6-II-1915 (22 h.)

Teatro Moderno

Compañía Francisco Morano

La Rioja (6-II-1915).

(3)

8-II-1915 (18,30 h.)

Teatro Moderno

Compañía Francisco Morano

La Rioja (8-II-1915).

(4) y (5) 29-IV-1929 (19 y 22,30 h.)

Teatro Bretón

Compañía Ricardo Calvo

La Rioja (28-IV-1929).

(6) y (7) $\quad 8$-II-1939 (18,30 y 22, 30 h.)

Teatro Bretón

Compañía del Teatro Nacional de la Falange

Director Luis Escobar

Nueva Rioja (8-II-1939). 
CERVANTES, Miguel de (1547-1616)

Los baños de Argel [COMEDIA]

$$
\text { 25-IV-1948 (19 h.) }
$$

Teatro de Educación y Descanso

Grupo de acólitos de la parroquia de San Bartolomé Nueva Rioja (25-IV-1948).

Los dos habladores [ENTREMÉS]

7-V-1905 (21,30 h.)

Teatro Bretón

Alumnos del Instituto de Enseñanza Media

La Rioja (9-V-1905).

(2) y (3) 10-II-1939 (18,30 y 22,30 h.)

Teatro Bretón

Compañía del Teatro Nacional de la Falange

Director Luis Escobar

Nueva Rioja (10-II-1939).

(4)

$$
\text { 12-II-1939 (17 h.) }
$$

Hospital de Legionarios

Compañía del Teatro Nacional de la Falange

Director Luis Escobar

Nueva Rioja (14-II-1939).

\section{La gitanilla ${ }^{1}$ [COMEDIA]}

(1) y (2) $\quad 8$-X-1922 (18,30 y 22,15 h.)

Adaptación de Diego San José

Teatro Bretón

\footnotetext{
${ }^{1}$ Aunque no es una obra teatral la incluimos por pertenecer a un autor del Siglo de Oro.
} 
Compañía Cobeña-Oliver

Nueva Rioja (8-X-1922).

La guarda cuidadosa [ENTREMÉS]

(1)

$$
\begin{aligned}
& \text { 7-IV-1942 (19,15 h.) } \\
& \text { Teatro Bretón } \\
& \text { Teatro Español Universitario } \\
& \text { Director Modesto Higueras } \\
& \text { Nueva Rioja (7-IV-1942). }
\end{aligned}
$$

El retablo de las maravillas [ENTREMÉS]

(1)

$$
\begin{aligned}
& \text { 1-IX-1933 } \\
& \text { Teatro Moderno } \\
& \text { Grupo La Barraca } \\
& \text { Directores: Federico García Lorca y Eduardo Ugarte } \\
& \text { La Rioja (2-IX-1933). } \\
& \text { 7-IV-1942 (19,15 h.) } \\
& \text { Teatro Bretón } \\
& \text { Teatro Español Universitario } \\
& \text { Director Modesto Higueras } \\
& \text { Nueva Rioja (7-IV-1942). }
\end{aligned}
$$

ENCINA, Juan del (1468-1529)

Égloga pastoril [ÉGLOGA]

$$
\begin{aligned}
& \text { 3-I-1946 } \\
& \text { Adaptación de Jiménez Caballero } \\
& \text { Teatro Bretón } \\
& \text { Grupo de jóvenes de Acción Católica } \\
& \text { Nueva Rioja (4-I-1946). }
\end{aligned}
$$


LOPE DE VEGA, Félix (1562-1635)

El castigo sin venganza [TRAGEDIA]

(1)

10-II-1921 (noche)

Teatro Moderno

Compañía del Teatro Español de Madrid

Directores: Jacinto Benavente y Ricardo Calvo

La Rioja (9-II-1921).

La discreta enamorada [COMEDIA]

(1)
15-III-1945 (19,30 h.)
Arreglo de José Eizaga
Teatro Bretón
Cuadro Artístico del Instituto de Enseñanza Media
Nueva Rioja (15-III-1945).

La estrella de Sevilla [COMEDIA]

(1)

20-IX-1935 (19 h.)

Adaptación de José Eizaga

Teatro Bretón

Compañía Lírica de Aficionados ${ }^{2}$

La Rioja (17-IX-1935).

Fuenteovejuna [DRAMA]

(1)

1-IX-1933

Teatro Moderno

Grupo La Barraca

Directores: Federico García Lorca y Eduardo Ugarte La Rioja (2-IX-1933).

${ }^{2}$ En adelante, C.L.A. 
La gala de Medina o el caballero de Olmedo [DRAMA]

4-VI-1946 (19,30 h.)

Teatro Bretón

Cuadro Artístico de Educación y Descanso

Nueva Rioja (29-V-1946).

(2)

5-VI-1946 (19,30 h.)

Teatro Bretón

Cuadro Artístico de Educación y Descanso

Nueva Rioja (29-V-1946).

(3)

6-VI-1946 (19,30 h.)

Teatro Bretón

Cuadro Artístico de Educación y Descanso

Nueva Rioja (6-VI-1946).

La niña boba [COMEDIA]. Adaptación de La dama Boba.

19-IX-1909 (noche)

Teatro Bretón

Compañía La Palma-Reig

La Rioja (19-IX-1909).

(2)

8-XI-1921 (18,30 h.) [Buen maestro es amor o la boba discreta $\left.^{3}\right]$

Arreglo de José Crespo

Teatro Bretón

Compañía Carmen Cobeña

La Rioja (8-XI-1921).

(3)

9-XI-1921 (22,15 h.) [Buen maestro es amor o la boba discreta]

Arreglo de José Crepo

Teatro Bretón

${ }^{3}$ El título entre corchetes es el dado a la obra en cada ocasión. 
Compañía Carmen Cobeña

La Rioja (9-XI-1921).

(4) y (5) 11-I-1936 (19 y 22,30 h.) [La dama boba

Adaptación de Federico García Lorca

Teatro Bretón

Compañía Margarita Xirgu

Director Cipriano Rivas Cherif

La Rioja (11-I-1936).

(6) y (7) 5-II-1945 (19,15 y 22,30 h.)

Teatro Bretón

Compañía Guerrero-Romeu

Nueva Rioja (4-II-1945).

MORETO, Agustín (1618-1669)

El desdén con el desdén [COMEDIA]

(1)

20-VII-1915 (21,45 h.)

Teatro Bretón

Compañía Guerrero-Mendoza

Director Fernando Díaz de Mendoza

La Rioja (20-VII-1915).

(2)

17-III-1923 (18,30 h.)

Teatro Bretón

Compañía Carmen Moragas

La Rioja (17-III-1923).

QUIÑONES DE BENAVENTE, Luis (1589-1679)

Los sacristanes burlados [ENTREMÉS]

(1)

7-IV-1942 (19,15 h.)

Teatro Bretón 
Teatro Español Universitario

Director Modesto Higueras

Nueva Rioja (7-IV-1942).

ROJA ZORRILLA, Francisco de (1607-1648)

Amo y criado [COMEDIA]

(1)

9-III-1912 (18 h.)

Refundición de Tomás Luceño

Teatro Bretón

Compañía dirigida por Francisco Morano

La Rioja (9-III-1912).

RUEDA, Lope de (m. 1565)

Las aceitunas [PASO]

(1)

$$
\begin{aligned}
& \text { 5-VII-1939 (19,15 h.) } \\
& \text { Cinema Social } \\
& \text { Teatro Español Universitario } \\
& \text { Nueva Rioja (5-VII-1939). }
\end{aligned}
$$

La tierra de Jauja [PASO]

(1)

5-VII-1939 (19,15 h.)

Cinema Social

Teatro Español Universitario

Nueva Rioja (5-VII-1939).

(2) y (3)

27-II-1941 (18,30 y 22 h.)

Teatro Bretón

Varios grupos de aficionados

Nueva Rioja (27-II-1941). 
RUIZ DE ALARCÓN, Juan (1581-1639)

La verdad sospechosa [COMEDIA]

(1) y (2) 9-II-1939 (18,30 y 22,30 h.)

Teatro Bretón

Compañía del Teatro Nacional de la Falange

Director Luis Escobar

Nueva Rioja (9-II-1939).

TIRSO DE MOLINA (1579-1648)

El vergonzoso en palacio [COMEDIA]

(1) y (2) $\quad 15-$ III-1923 (18,30 y 22,15 h.)

Teatro Bretón

Compañía Carmen Moragas

La Rioja (15-III-1923).

(3) y (4) 26-IX-1946 (19,45 y 23 h.)

Teatro Bretón

Compañía Guerrero-Romeu

Nueva Rioja (26-IX-1946).

VÉLEZ DE GUEVARA, Luis (1578-1645)

La luna de la sierra [DRAMA]

$$
\begin{aligned}
& \text { 6-III-1912 (22 h.) } \\
& \text { Refundición de Cristóbal de Castro } \\
& \text { Teatro Bretón } \\
& \text { Compañía dirigida por Francisco Morano } \\
& \text { La Rioja (6-III-1912). }
\end{aligned}
$$


Reinar después de morir [DRAMA]

(1) y (2) 13-III-1923 (18,30 y 22,15 h.)

Teatro Bretón

Compañía Carmen Moragas

La Rioja (13-III-1923).

(3) y (4) 10-XII-1931 (18,30 y 22,30 h.)

Teatro Bretón

Compañía Carmen Moragas

Nueva Rioja (10-XII-1931).

(5) у (6) 29-IV-1944 (19,45 y 22,45 h.)

Teatro Bretón

Compañía Guerrero-Romeu

Nueva Rioja (29-IV-1944).

VICENTE, Gil (1470-1536)

Auto de la Sibila Casandra [AUTO]

(1)
3-I-1946
Teatro Bretón
Grupo de jóvenes de Acción Católica
Nueva Rioja (4-I-1946).

Hasta aquí las fichas de las obras representadas. Veamos ahora algunos ejemplos de las reseñas periodísticas dedicadas a estas funciones" ${ }^{4}$ :

Con escasa concurrencia púsose anoche en escena en el Bretón de los Herreros la conocida comedia El Alcalde de Zalamea.

Obtuvo una interpretación aceptable. Menudearon los aplausos para el celebrado actor don Donato Jiménez que a pesar de sus años hizo con brío el papel de Pedro Crespo.

\footnotetext{
${ }^{4}$ En el mismo orden que hemos expuesto autores y obras.
} 
Lola Bremón, bien en Isabel, y de los demás el mejor el señor Zama, por el modo de caracterizar al rey don Felipe II. [...]

La Rioja, 30-IX-1908.

\section{Teatro Bretón}

Tras el título de la obra, el programa oficial rezaba con referencia a «El alcalde de Zalamea», «la más genial creación de Morano», y esto aunque en otras ocasiones debe acogerse con reserva, por lo frecuente que es repetirlo, en la de ayer no hay duda de que era verdad, pero a medias solamente. A medias porque si es una genial creación de Morano, Morano ha sido para fortuna suy a yrestigio del arte escénico, genial creador de otros caracteres teatrales. Cierto es, sin embargo, que el de este alcalde labriego, modelo de ciudadanía y de civilidad en su tiempo, que sabía cuántos respetos debía y de cuántos era merecedor, este alcalde que representa la comprensión, el vigor, la astucia y la altivez que se juntan en el alma castellana, adquiere plena robustez teatral, servida por el talento y facultades de don Francisco Morano, tan magnífico actor como admirable declamador de versos. [...]

En la jornada de la tarde de ayer, las ovaciones del auditorio fueron un triple homenaje; al creador genial del personaje, a la significación de aquel alcalde y a su genial intérprete. [...]

La Rioja, 25-I-1930.

Las bodas de oro de la compañía Enguídanos

Ayer, viernes, se cumplieron los cincuenta años de la fundación de la compañia de comedias y dramas Enguídanos.

Es admirable el esfuerzo y la férrea voluntad que suponen este logro de medio siglo de vida artística a través de toda España, y más aún cuando durante tan dilatado periodo se ha sabido sostener un prestigio de absoluta dignidad artística, y se ha realizado una copiosa y fructífera labor. No es posible reflejar aqui el mérito de todo esto.

Sin embargo, el público, que estima y admira a estos buenos comediantes, lo ha comprendido perfectamente y ayer, con motivo de la función conmemorativa del cincuenta aniversario de vida artística, les hizo objeto de un cariñosísimo homenaje de admiración y simpatía. El teatro Lope de Rueda se vio abarrotado de público, que ovacionó con verdadero entusiasmo y afecto a todos los componentes de la Compañía Enguídanos, que en la representación de «El Alcalde de Zalamea», excelente y cuidada, puso de manifiesto su notable nivel artístico. [...]

Nueva Rioja, 26-VI-1943. 


\section{Teatro Bretón}

No nos habíamos equivocado al suponer el interés del público inclinado a admirar la siempre interesante comedia del gran dramaturgo don Pedro Calderón, La vida es sueño.

Con más puntualidad que nunca, aparecieron desde las primeras escenas ocupadas casi todas las localidades del patio y bastante nutridas las galerías.

Los versos sonoros, fáciles y armoniosos de que está esmaltada la obra, así como los pensamientos y situaciones viriles que hermosean las situaciones principales, fueron celebrados con entusiastas y espontáneos aplausos que debieron conmover las cenizas del insigne artista de la palabra rimada y dulce.

No son precisos los recursos de actor tan ensalzado como el señor Fuente, $n i$ actriz tan discreta cual la señora Guillén, para augurar el éxito de una producción llamada a sobrevivir a muchas generaciones.

El triunfo de anoche, como la entrada, fue debido a Calderón de la Barca. ¡Y cosa extraña! La taquilla traducía en vil metal la fama del inolvidable poeta, al paso que La vida es sueño no rinde ni un céntimo a la familia, por haber pasado la comedia al dominio público. [...]

Fray-CIRILO

La Rioja, 6-VI-1902.

\section{Teatro Bretón}

Si Ricardo Calvo, el eminente actor, no fuera el mantenedor único de nuestro teatro clásico y hasta del teatro clásico universal, en cuanto ha sido incorporado a nuestra escena, sería el Pontífice máximo, del culto a nuestros dramáticos del «Siglo de Oro», porque nadie mejor que él da realce a los versos magníficos de Calderón, de Lope, de Tirso y de Guevara, con esas maravillosas dotes de declamador, que parecen servidas por los manes de aquellos ingenios para sostén de su propia gloria.

Por eso la representación de una de estas obras, como ayer la de «La vida es sueño", del don Pedro insigne, impone respeto, obliga al recogimiento, cautiva la atención «religiosamente» y el público escucha devoto como en los labios del declamador estupendo sus magníficos versos, joyantes, que expresan imágenes que tienen fulgores de piedras preciosas, y pensamientos delicados como el colorido de las flores, y firmes ideas, tenaces y sutiles como un buido acero, suspende el aliento y atiende sojuzgado por su propia emoción a la que va naciendo del desarrollo de la obra y progreso de la representación.

Gracias le sean dadas al insigne actor por el servicio que presta a la memoria de nuestros grandes autores del Siglo de Oro, y, también por el que hace 
al público contemporáneo, no exhumando ruinas gloriosas, que como las del Partenón tienen sólo el prestigio de una sugerencia histórica, sino sacando, esos vivos monumentos de valor universal en el tiempo y en el espacio, del secuestro en que hoy están puestos por incuria e inepcia de muchos comediantes, que no han querido o no han podido aprender a declamar el verso.

«La vida es sueño» de ayer no hay que decir que tuvo en Ricardo Calvo, un admirable «Segismundo». El auditorio aplaudió muchos parlamentos maravillosamente declamados por el gran actor y estalló al final de todos los actos en cerradas salvas de aplausos, obligando a levantarse una y más veces la cortina y tributando a Ricardo Calvo el merecido homenaje de admiración y de cariño.

Irene y Consuelo Guerrero de Luna, Pedro Guirao, Luis Calvo, Guillermo Marín, Antonio Estévez y los demás intérpretes interpretaron los papeles a su cargo, con la debida eficacia.

La Rioja, 30-IV-1929.

Tercer Centenario del Quijote

\section{EN LOGROÑO}

En el teatro

Magnífico aspecto ofrecía nuestro coliseo en la función de gala que en honor al inmortal Manco de Lepanto se celebró la noche del domingo último.

Se hallaba el teatro de bote en bote, sobre todo en plateas, palcos y butacas, en donde se encontraban las personas más distinguidas de nuestra capital, siendo de observar que la mayor parte de las señoras, accediendo a los ruegos de la prensa local, asistieron sin sombreros, pues sólo se vieron cuatro de éstos: las demás adornaron sus cabezas con bonitas flores, con tanto gusto colocadas, sobre rostros tan graciosos que hacían dudar de si éstos adornaban a aquéllas o las flores a las bellas.

A las nueve y media comenzó la función con la representación de la Cervantina, compuesta por don José María Ovejero [...].

El entremés «Los dos habladores» fue interpretado con mucho esmero por las señoritas Ángela Ruiz [...]

La Rioja, 9-V-1905.

Las funciones con que se despidió ayer en el Bretón el Teatro Nacional de Falange, respondieron cabalmente a cuanto podía esperarse del gusto artístico depuradísimo de su animador, y de los merecimientos de los comediantes. El programa todo, fue servido con interpretación que pudiéramos decir reverente 
y plena de dignidad. Al auditorio le produjo impresión inmejorable en todas sus partes.

Gracioso, deliciosamente gracioso el entremés «Los dos habladores» atribuido a Cervantes, lo que basta para señalar cuáles serán las galas del ingenio que le prestan garbo y donosura.[...]

Muchísimos y muy calurosos fueron los aplausos otorgados a los artistas, cuyo noble empeño y cuyo acertado trabajo merecen y obtienen los más favorables pronunciamientos. [...]

La Rioja, 10-X-1922.

Bretón

«La Gitanilla», adaptación que Diego San José ha hecho a la escena de la novela de Cervantes, del mismo título, fue la obra representada, con el primor que toca por la compañía Cobeña-Oliver.

La adaptación está bien hecha. La obra fue muy bien presentada y mejor representada por Carmen Cobeña Oliver, Carmen Cobeña y [...] principalmente.

Sin embargo justo es decir que por no resultar muy teatral gustó sinceramente pero no llegó a entusiasmar, y es que al adaptador se le ofreció dificultad de escenificar la vida que necesitan para la escena, a personajes que el novelista pintó de mano maestra. Claro es que este reparo leve no quiere decir que carezca la comedia del mérito del que la novela está tan sobrada.

La Rioja, 10-X-1922.

La velada artística de ayer

Agradable y variada resultó la fiesta celebrada ayer en el Teatro Bretón de los Herreros a beneficio de la Bolsa del Libro con la intervención del Teatro Español Universitario y la Tuna del Distrito de Madrid a su paso por nuestra capital. [...]

Seguidamente fueron puestos en escena por el T.E.U. tres entremeses, modelos en su género, titulados «Los sacristanes burlados», «La guarda cuidadosa»y «El retablo de las maravillas», el primero de ellos de Quiñones de Benavente, que tan magistralmente supo retratar toda la sociedad de nuestro siglo XVII, $y$ los otros dos del inmortal Cervantes, que no sólo dio forma poética al entremés, sino que consiguió darle elevado rango en nuestra dramática.

La interpretación y presentación de estas bellísimas piececitas fue muy cuidada, mereciendo todos los cálidos aplausos que el público les tributó. [...]

Nueva Rioja, 8-IV-1942. 


\section{TEATRO}

Brillantísima, en efecto, ha resultado la interesante velada teatral celebrada en el Bretón por los estudiantes del Instituto de Enseñanza Media en honor de su glorioso Patrono Santo Tomás de Aquino, y que, por coincidir la fecha primeramente señalada para su celebración con los días de la Santa Misión, fue trasladada a la del 15 de los corrientes.

Comenzó la fiesta con la representación, por el Cuadro Artístico del Instituto, de la magnífica comedia de Lope de Vega «La discreta enamorada», arreglada a la escena actual, con tacto y gusto que merecen los mayores elogios, por el prestigioso don José Eizaga, que agrega con ello un nuevo y legítimo triunfo a su destacada personalidad teatral.

La interpretación notabilísima mereció los mayores elogios que nosotros tributamos por igual a todos los componentes del reparto, en el que, con papeles de mayor o menor importancia —aunque todos servidos con la misma admirable perfección - figuraban los siguientes aficionados:

Julia J. Jiménez, Dorita G. Espinosa, Julia Hernando Otero, José Díaz Azcona, Miguel M. Galilea, José María Echavarri Solozábal, José Luis Gaviria Martínez, José Luis Chavarría Madrazo, Carlos Briz Castillo, Justiniano L. Peña, Rodolfo M. Ganuzas.

El público, que llenaba totalmente la sala, tributó a todos, a lo largo de los tres actos de la obra, calurosísimas y muy justas salvas de aplausos. [...]

Nueva Rioja, 17-III-1945.

\section{EL HOMENAJE A LOPE DE VEGA}

Con gran concurrencia se verificó ayer en el Teatro Bretón la función homenaje a Lope de Vega, patrocinada por el excelentísimo Ayuntamiento y Ateneo Riojano y organizada por la C.L.A. Los elementos de esta entidad artística, que tiene conquistados tantos lauros y recibidos tan calurosos aplausos, cosechó nuevamente ayer muchos de unos y otros por la interpretación acertadísima que dio al drama de Lope «La estrella de Sevilla», no sólo venciendo las dificultades de los versos, sino declamándolos con seguridad y adecuados y justísimos acentos, meritoria labor que el nutrido auditorio comentó con simpatía y con elogio.

La presentación de la obra en escenario sintético fue asimismo digna de aplauso. [...]

La Rioja, 21-IX-1935. 


\section{Presentación de «La Barraca»}

Nos vimos ayer gratamente sorprendidos con la presencia y actuación en el teatro Moderno de esta capital, de la entidad artística Teatro Universitario «La Barraca» (U.F.E.H), la cual viene cumpliendo la misión de, a la manera de la antigua farándula, dar a conocimiento de los vecindarios, especialmente rurales, las más destacadas obras de nuestro Teatro Clásico.

De las excelentes calidades del espectáculo son garantía los directores artísticos, el inspiradísimo poeta Federico García Lorca y Eduardo Ugarte.

Como el paso de «La Barraca» había de ser rápido y era necesario encargarse de la organización del acto teatral, auxilió a los directores artísticos en este menester, el presidente del «Ateneo Riojano» don Gonzalo Cadarso quien, con varios miembros de la Junta, procedió activamente para lograr que el espectáculo contara con un público tan nutrido que llenó el teatro con exceso y en gran parte muy selecto.

Los comediantes del Teatro Universitario, alumnos que se preparan en invierno para actuar durante las vacaciones en la escena de «La Barraca», interpretaron una antología, acertadamente hecha por Federico García Lorca, del drama de Lope «Fuenteovejuna», y también «El retablo de las maravillas», de Cervantes.

La representación de una y otra obra, es original y cuidada. El decorado de la primera pertenece a Alberto y el de la segunda es debido a Manuel Ángeles Ortiz, y los dos merecen sinceros elogios.

La parte musical del drama fue muy grata al auditorio, tanto que «el baile de las agachaditas» hubo de ser repetido.

Por lo que toca a la ejecución, serían pocas todas las alabanzas. Los escolares han sabido compenetrarse con los personajes a su cargo y, como tienen perfectamente aprendida la letra de los papeles, la incorporación escénica es, por parte de cada uno de ellos, aunque, naturalmente, en proporción a la importancia del cometido, sencillamente admirable.

El público manifestó frecuentemente, con grandes aplausos, la excelente impresión que le producía el espectáculo y los comediantes, y al terminar la función hizo objeto a «La Barraca» de los pronunciamientos más favorables, reconociendo el valor cultural de sus actuaciones. [...]

La Rioja, 2-IX-1933.

Teatro

La noche del domingo se puso en escena la comedia de Lope de Vega La niña boba $[\ldots]$. 
La entrada fue muy regular y el público selecto saboreó con deleite las ranciedades de nuestro gran comediógrafo.

El oro viejo de sus versos castellanos brilló con vivos destellos al brotar de los labios de Enriqueta [...].

La señora Badillo ha realizado notabilísimos progresos en su carrera artística, desde la última vez que en Logroño la aplaudimos.

Luz de las Heras, muy querida y estimada de nuestro pueblo, dio relieve sobresaliente a su papel, y todos cosecharon aplausos y llamadas a escena.

No hablamos de ellos por no permitírnoslo la falta de espacio; pero podemos asegurar que, en conjunto, es una de las compañias más completas que hemos admirado. [...]

La Rioja, 21-IX-1909.

\section{Teatros y cines}

La presentación en la escena de nuestro primer coliseo de la compañía de la genial actriz Margarita Xirgu, revistió caracteres de extraordinario acontecimiento artístico.

La eximia comediante y sus huestes pusieron en escena «La dama boba», de Lope de Vega, adaptada al teatro moderno por Federico García Lorca y lo hicieron de tal manera por lo que toca a la presentación y a la ejecución que puede considerarse la jornada de ayer como de verdadera misa de arte, capaz de satisfacer las mayores exigencias espirituales.

Pocas veces, acaso ninguna, se ha visto en el Teatro Bretón de los Herreros una representación de mayor entidad artística, puesto que a las exigencias que ofrecía la lindísima comedia del Fénix de los Ingenios respondió una ejecución espléndida en presentación escénica y valores interpretativos, en la que descolló con todo su merecido prestigio, Margarita Xirgu, como actriz única, que incorporó la figura femenina protagonista con una prestancia, con una justeza, con una donosura y con una riqueza de matices de las que sólo viéndola puede formarse una idea cabal.

No sería justo dejar de poner de relieve que la acompañaron en su interpretación singularísima Pedro López Lagar, Alberto Contreras, Enrique Álvarez Diosdado, Alejandro Maximino; Amelia de la Torre, maravillosa en su dicción; Amelia Sánchez Ariño, tan justamente graciosa y tan segura, que es acaso la primera dama de carácter de la escena española; Antoñita Calderón, y, en fin, cuantos tenían juego en el reparto.

El entreverado de canciones clásicas avaló no poco la producción escénica y, en una palabra, obligados por la sinceridad, no exenta de emoción cordial, 
hemos de afirmar que sólo de exquisito espíritu artístico y de un recio temperamento, cabe esperar la presentación y la interpretación cuidadísima que Margarita Xirgu dio a la obra.

El público, nutrido, pero no tanto - sin que acertemos a explicarnos por qué-, como merecían no sólo lo que tenía la significación de un homenaje a Lope de Vega, sino los méritos excepcionales de la actriz titular y de las huestes que acaudilla, francamente emocionado con la más firme, más intensa, más cabal, en suma, de las emociones estéticas, subrayó con grandes aplausos la aparición en escena de la eminente comediante y con ovaciones entusiastas algunos pasajes y al final de todos los actos, cuando con los intérpretes en el palco escénico para agradecer la espontánea expresión del sacudimiento emotivo, se levantó el telón varias veces. [...]

La Rioja, 12-I-1936.

[...] Por la noche, en la interpretación de «El castigo sin venganza» de Lope de Vega, se hicieron aplaudir muy merecidamente las señoritas Moragas y Seco y los señores Fuentes y Calvo, que destacaron maravillosamente sus papeles.

Los demás entonaron el conjunto que fue acabado y tuvieron la debida participación en las ovaciones grandes que se tributaron a las primeras partes.

Al final de la obra hubo de levantarse la cortina varias veces.

La Rioja, 11-II-1921.

\section{TEATRO}

Se tributó anoche a María Guerrero y su compañía una despedida cariñosa, entusiasta.

Hasta seis veces hicieron los aplausos del público que se alzara la cortina al final de la obra.

Era ésta la mortal comedia en verso de Moreto «El desdén con el desdén», y sus profusos y bellos discreteos, la múltiple variedad de metros y de pensamientos, fue debidamente apreciada, toda vez que la dicción de los artistas es tan perfecta, y singularizando hablaremos de Guerrero Díaz de Mendoza, que parece como si se recreara en matizar los versos cuando rozan los labios para salir camino de nuestros oídos.

Temíamos que «El desdén con el desdén» se hiciera algo pesado atendiendo a la simplicidad de su argumento, que ocupa tres actos, pero ello no fue así.

Se lleva la obra ligeramente y el diálogo se dice tan fluidamente como lo escribió el autor y tan a maravilla como él pudo soñar, y el público asiste más que complacido, encantado, al desarrollo de la obra. 
María Guerrero se hizo ovacionar anoche en distintas ocasiones; las que al final se tributaron a ella y a su ilustre marido fueron tan persistentes como unánimes que, como al comienzo de estas líneas decimos, se alzó el telón por seis veces, y persistimos en hacerlo notar para que quede de modo más firme consagrado el triunfo, toda vez que tan envidiable circunstancia se dio en rarísimas ocasiones, en las que intervinieron prestigiosos de la categoría de los de anoche. [...]

La Rioja, 21-VII-1915.

Otras ocupaciones periodísticas nos impidieron asistir ayer tarde al estreno en Bretón de los Herreros de "Amo y criado», obra de Rojas, refundida por Luceño.

Al público, según las impresiones que recibimos, no le satisfizo.

No queremos entrar en otro orden de observaciones, ya que no vimos la producción estrenada.

Para sus intérpretes hubo aplausos [...].

MONTEMAR

La Rioja, 10-III-1912.

\section{Teatro Español Universitario}

Hizo ayer su segunda salida escénica el Teatro Español Universitario. Lugar de la brillante demostración: el Cinema Social. [...]

[...]. La «carta artística» ha sido dominante en entremeses, pero cuando son seleccionados como los de ayer, cuatro de ellos valen, sin duda, por una comida excelente.

Por otra parte el programa, sin dejar de ofrecer dificultades, se prestaba a una más segura interpretación. Imponía menos fatiga a los comediantes. No exigía sostener el tipo ni el carácter. $Y$ así, más leve la carga, pudo ser llevada con mayor holgura. Un mérito más: el de la justeza.

Lope de Rueda, autor y actor como Shakespeare, fue elegido digno de honor $y$ sus pasos «La tierra de Jauja» $y$ «Las aceitunas» pudieron ser parangonados con los entremeses «El mal ángel» $y$ «Ganas de reñir», de los hermanos Álvarez Quintero.

La interpretación de unos y otros puede calificarse por deliciosa. Y se echó de ver cómo junto al garbo y la gracia andaluza de los personajes quinterianos resaltaba la donosa socarronería de aquellos otros, precursores de los que habían de ser grandiosos en nuestro Siglo de Oro. Trabajos de pícaros y bobos, afanes insensatos por las naderías de un lejano porvenir, son acha- 
ques de todos los tiempos. En los pasos de Lope de Rueda, como en los pasillos de los autores de Sevilla, se llega a la moraleja tras un diálogo ligero, fácil, salpimentado. Tan distantes unos y otros en el tiempo y, sin embargo, nada ceden los antiguos a los de hoy en cualidades teatrales ni, ciertamente, en literarias. [...]

Nueva Rioja, 6-VII-1939.

\section{Espectáculos}

Como espectadores de la representación que en la escena del Bretón de los Herreros hizo ayer de «La Verdad Sospechosa», el magnífico conjunto del Teatro Nacional de la Falange confirmamos sin reserva alguna el juicio que expusimos ayer. Y aún podríamos decir que, si cabe, los caracteres, las notas dominantes que acusábamos ponderativamente, cobraron mayor relieve en esta segunda actuación.

Cierto que en ella se daba la circunstancia de que la ejecución de una obra de nuestro «Siglo de Oro» tuviera, no honores, que por méritos de la incorporación escénica no le faltaron, sino verdadera realidad de estreno. Exaltable a más no poder es el propósito de este Teatro, que destaca y honra, y que da a conocer la obra de nuestros ilustres ingenios, de los que el gran público apenas conoce otra cosa que sus nombres esclarecidos. Demostración de lo provechoso de esta tarea fue la impresión que en el numerosísimo auditorio produjo la comedia de Ruiz de Alarcón. No puede sorprender, cuando en la producción del ingenio se dan valores universales como los que contiene la fábula. La mentira como instrumento que se vuelve contra quien la utiliza, es tema de todo tiempo y de toda la humanidad. Molière lo cultivó también; pero en desenvoltura, en gracia, en movimiento y en la sutileza del diálogo, nada cede la producción del nuestro, a la del autor francés.

El público atendió al juego escénico con atención intensa y dio suelta franca a la risa que suscitaba la acción tanto por sus situaciones cuanto por su diálogo salpimentado.

Por lo que a la ejecución toca, cuanto digamos en su alabanza será escaso. La igualdad, la tersura, la transparencia, la suavidad en los matices, le dieron rango de acontecimiento. No cabe superar tal acierto interpretativo.

Es, por singular, casi prodigioso, que un conjunto de comediantes, logre la misma manera dentro de las exigencias de la incorporación de cada uno de los personajes. Los efectos escénicos irreprochables y nuevos. La misma novedad dentro del acierto cabe elogiar en el decorado.

La concurrencia aplaudió calurosísimamente. [...]

Nueva Rioja, 10-II-1939. 
[...]. Después se interpretó, con la acostumbrada discreción, justeza e inmejorable conjunto la comedia de Tirso de Molina «El vergonzoso en palacio», obra modelo de nuestro teatro clásico.

Es la obra pródiga en ingenio y no le perjudican sus «gotitas» de conceptismo.

La producción tiene para sus intérpretes no pocas dificultades que la señora Moragas, la señorita López Lagar y los señores Monteagudo, García Leonardo y Mora supieron vencer tan airosamente que el público les aplaudió mucho.

La Rioja, 16-III-1923.

[...]. Por la noche se estrenó el drama clásico de don Luis Vélez de Guevara, «La luna de la sierra».

Pertenece la obra al Siglo de Oro de nuestra literatura y no hemos de describirla ahora.

Tributemos tan solo nuestro aplauso al refundidor, el exquisito poeta Cristóbal de Castro, y a los intérpretes señorita Villegas y Almiñana, y señores Morano, Perchicot y Vico. [...]

La Rioja, 7-III-1912.

\section{TEATROS Y CINES}

La compañia de Carmen Moragas, que ayer hizo su presentación en nuestro primer coliseo, alcanzó, como se aguardaba, un éxito muy lisonjero y muy merecido, al que no fueron ajenos las bellezas y primores de versificación y la emoción dramática de la magnífica obra de Vélez de Guevara «Reinar después de morir», resaltados con verdadera eficacia por el bien disciplinado conjunto y muy especialmente por el veterano comediante Ricardo Juste; Rafael Calvo, buen actor que prestó dignidad a su apellido, y más todavía por Blanca Jiménez, cuyos méritos se acrecientan de una a otra actuación considerablemente y Carmen Moragas, en la que la belleza y la voz son adorno de su talento y que interpretó a maravilla el primer papel femenino, matizándolo diestramente y declamando a perfección los nada fáciles aunque hermosos versos.

El auditorio, muy numeroso, aplaudió calurosamente al caer el telón tras cada jornada y al final de la obra y la cortina hubo de levantarse varias veces a requerimiento del público para que los comediantes recibieran a plena luz la justicia del batir de palmas.

La Rioja, 11-XII-1931. 


\section{TEATRO}

Los jóvenes de Acción Católica nos deleitaron ayer con un festival en el que representaron maravillosamente varias obras religiosas clásicas en las que hicieron gala de un arte exquisito. [...].

En segundo lugar figuraba en el programa la deliciosa pieza teatral del siglo XVI, original de Enzina y Torres Naharro, «Égloga pastoril». Está la obrita llena de sabrosa gracia y en ella brilla todo el limpio ingenio de nuestros grandes literatos del siglo XVI. Es como un cuadro sacado de uno de nuestros «belenes», y en su gracia van prendidos, como en aquéllos, numerosos anacronismos de indumentaria, pudiendo también encontrarse alguno en el diálogo. Es que la idea que brillaba en la mente de nuestros antiguos autores dramáticos era la de representar al pueblo español ante los Misterios de la verdadera Religión. El público acogió con gran simpatía, traducida en aplausos, la presentación de esta «Égloga pastoril».

A continuación fue presentado magníficamente el conocido «Auto de la Sibila Casandra» de Gil Vicente, que fue interpretado con acabada maestría y que tiene un fondo extraordinario de poesía y de gracia en su lenguaje de giros castizos. [...]

En esta velada quedó, pues, bien de manifiesto cómo puede agradar aún a los públicos nuestro teatro clásico, cuando sabe adaptarse a nuestra época, como en estas obras que ayer se representaron lo ha llevado a cabo Giménez Caballero.

Nueva Rioja, 4-I-1946.

Como podemos ver en estos ejemplos, las reseñas periodísticas sobre las obras relacionadas no son críticas teatrales propiamente dichas, ya que en la mayoría de ocasiones simplemente se limitan a hacer un elogio del autor y la obras en cuestión, parándose más en el ambiente que reinaba en la sala o elogiando a ciertos actores que en hacer comentarios verdaderamente críticos tanto de la obra como de la interpretación; sin embargo, esto no es privativo de la ciudad de Logroño, sino algo habitual en la mayoría de las capitales, que no contaban en las filas de los redactores periodísticos con especialistas en todas las materias que trataban.

A continuación vamos a analizar los datos relacionados anteriormente:

1. De un total de más de mil autores relacionados en nuestro trabajo, son únicamente doce $(1,2 \%)$ los que pertenecen al periodo literario que analizamos aquí: Calderón, Cervantes, Juan del Encina, Lope de Vega, Moreto, Quiñones de Benavente, Rojas Zorrilla, Lope de Rueda, Ruiz de Alarcón, Tirso de Molina, Vélez de Guevara y Gil Vicente. 
2. Frente a 2.786 títulos aparecidos en los escenarios logroñeses durante los primeros cincuenta años del siglo XX, tan solo $24(0,87 \%)$ pertenecen a autores de los siglos XVI y XVII; además, la diferencia de obras representadas entre ellos mismos es más que notable: seis títulos de Calderón y cinco de Cervantes frente a uno o dos del resto de ellos.

3. Entre 11.291 funciones realizadas durante el periodo, las que corresponden a títulos de obras clásicas son un número pequeño, 78 (0,7\%), la mayoría de las cuales pertenecen a Calderón, con 31 representaciones. El promedio de representaciones de obras clásicas por año según este dato sería de algo menos de 1,6\%. Sin embargo, en este caso la distribución anual de estas funciones es muy diferente, ya que en la mayoría de los años no se da ninguna; los años con más representaciones son 1939 (9 funciones) y 1946 (7 funciones); el resto tienen entre una y cinco funciones:

- cinco funciones: 1915, 1921 y 1923

— cuatro funciones:1941 y 1943

— tres funciones: 1912 y 1942

- dos funciones: 1912, 1919, 1922, 1924, 1929, 1930, 1931, 1933, 1940,1944 y 1947

— una función: 1902, 1905, 1908, 1909, 1935 y 1948.

4. Respecto a las compañías, de un promedio anual de 92 elencos que actúan en los escenarios logroñeses en este medio siglo, sólo 16 grupos profesionales y 8 de aficionados, en el total de todo el periodo, dedican alguna de sus funciones a este tipo de obras.

5. En el caso de los locales en los que se efectúan las representaciones de obras clásicas, la situación es similar; las encontramos en seis (15\%) de los cincuenta locales que funcionaron como escenarios en Logroño durante este periodo estudiado. Uno de ellos, el Hospital de Legionarios, no es un escenario habitual, sino que se utilizó sólo para ciertas funciones concretas en una determinada situación.

6. A pesar de que la figura del director de escena no tenía en la época estudiada la importancia que ha cobrado en la actualidad, encontramos citados cinco nombres como directores de grupos profesionales y tres de los aficionados, aunque entre los primeros dos de ellos, Morano y Díaz de Mendoza, distan bastante de lo que es un director de escena 
actual y son más bien los directores de la compañía, frente a otros que habían entendido ya la función de este personaje, como Rivas Cherif, Lorca o Modesto Higueras.

7. En cuanto a las adaptaciones o refundiciones, diez son los nombres que se nos citan como realizadores de estas tareas, en nueve de los títulos representados. Un caso especial es el de la adaptación de la novela de Cervantes, La gitanilla, que se convierte en obra teatral en manos de Diego San José. Entre estos adaptadores se encuentra el popular autor logroñés José Eizaga, que también realizaba labores de dirección en varios elencos teatrales, y otros autores conocidos de la época como Adelardo López de Ayala, Federico García Lorca o Tomás Luceño.

8. Hablaremos en último lugar de los géneros. En este caso, aparecen todos los que podemos encontrar en el teatro del Siglo de Oro, desde el auto a la tragedia. Las obras relacionadas son: un auto, nueve come$\operatorname{dias}^{5}$, seis dramas, una égloga, cuatro entremeses, un paso y una tragedia.

A tenor de esta información analizada, es evidente que en un periodo de tanta duración (1901-1950) y con una abundante actividad teatral, la cantidad de funciones dedicadas a nuestros clásicos del Siglo de Oro se convierte casi en mera anécdota; está muy claro que los clásicos españoles no fueron precisamente los autores que más veces fueron llevados a los escenarios logroñeses. Sin embargo, hallamos el hecho curioso de que los pocos que lo hicieron fueron representados por compañías profesionales y también por grupos de aficionados, en algunos casos de la propia localidad (alumnos del Instituto, Cuadro de Educación y Descanso, C.L.A.).

¿A qué es debido, por tanto, esta escasez de obras clásicas en los repertorios teatrales? Parece evidente que no lo es por un mal recibimiento del público, pues ya hemos visto en las reseñas periodísticas que éste acudía cuando se ofrecían estos títulos en los programas, porque además los elencos profesionales que las realizaban eran los de más prestigio durante la época, como los de Francisco Morano, Enrique Borrás, María Guerrero o Margarita Xirgu, por poner sólo algunos ejemplos.

A esto habría que añadir la utilización que se hizo de esta serie de obras durante épocas concretas y con fines bien distintos. Durante la Segunda Re-

${ }^{5}$ La adaptación de La gitanilla aparece como comedia. 
pública, el fin el grupo dirigido por Lorca, La Barraca, utilizó a los autores clásicos para llevar a los pueblos el conocimiento del arte teatral; tras la Guerra Civil, la Dictadura franquista utilizó estos títulos como ejemplo de exaltación patriótica a través de grupos teatrales como el de la Falange o el Teatro Universitario.

Parece más bien que la escasez se debía a las pocas compañías que estaban especializadas en este tipo de obras que, por su dificultad, no estaban al alcance de todos los actores (ni de todos los públicos); la cantidad de compañías dedicadas al género lírico o al teatro contemporáneo (y no al más selecto en la mayoría de ocasiones) era muchísimo mayor que las anteriores, por lo que su presencia en los escenarios de Logroño y de otras capitales era más asidua teniendo en cuenta, además, que su presencia era también más solicitada por el público de todas las capas sociales. Pese a ello, nuestras obras clásicas gozaron de una presencia interesante en la ciudad de Logroño.

NOTA: Mi tesis de doctorado y su cartelera pueden consultarse en la sección «Estudios sobre teatro» de la página electrónica del Centro de Investigación, dirigido por el profesor José Romera Castillo: http://www.uned.es/centro-investigacion-SELITEN@T. 